\title{
Comment on Shvedova et al. (2016), "gender differences in murine pulmonary responses elicited by cellulose nanocrystals"
}

\author{
Jo Anne Shatkin ${ }^{1 *}$ and Günter Oberdörster ${ }^{2}$
}

\begin{abstract}
A recent publication in "Particle and Fibre Toxicology" reported on the gender differences in pulmonary toxicity from oro-pharyngeal aspiration of a high dose of cellulose nanocrystals. The study is timely given the growing interest in diverse commercial applications of cellulose nanomaterials, and the need for studies addressing pulmonary toxicity. The results from this study are interesting and can be strengthened with a discussion of how differences in the weights of female and male C57BL/6 mice was accounted for. Without such a discussion, the observed differences could be partially explained by the lower body weights of females, resulting in higher doses than males when standardized to body weight or lung volume. Further, few conclusions can be drawn about the pulmonary toxicity of cellulose nanocrystals given the study design: examination of a single high dose of cellulose nanocrystals, administered as a bolus, without positive or negative controls or low dose comparisons, and at an unphysiological and high dose rate. Simulating the bolus type delivery by inhalation would require a highly unrealistic exposure concentration in the $\mathrm{g} / \mathrm{m}^{3}$ range of extremely short duration. A discussion of these limitations is missing in the paper; further speculative comparisons of cellulose nanocrystals toxicity to asbestos and carbon nanotubes in the abstract are both unwarranted and can be misleading, these materials were neither mentioned in the manuscript, nor evaluated in the study.
\end{abstract}

Keywords: Cellulose nanocrystals, Cellulose nanomaterials, Inhalation, Gender differences, Pulmonary toxicity

\section{Commentary}

In their recent publication, "Gender differences in murine pulmonary responses elicited by cellulose nanocrystals", Shvedova et al., [1] exposed C57BL/6 mice by pharyngeal aspiration to suspensions of cellulose nanocrystals (CNCs) (40 $\mathrm{\mu g} / \mathrm{mouse} /$ day; cumulative dose of $240 \mu \mathrm{g} /$ mouse). The authors employed a variety of biochemical, cellular, histopathological and physiological measures to compare responses observed in the lungs of male and female mice. As strong advocates for proactive approaches to assessing the safety of nanomaterials, we would be most interested in these findings, however the study design limits the ability to relate the results to effects from $\mathrm{CNC}$ exposure under realistic conditions.

\footnotetext{
* Correspondence: jashatkin@vireoadvisors.com

'Vireo Advisors LLC, Boston, MA, USA

Full list of author information is available at the end of the article
}

The authors state that the "primary goal of this study was to determine whether gender affects pulmonary function, global mRNA expression, and cytokine/chemokine inflammatory responses in the lung of C57BL/6 mice". The findings of observed gender differences, with females showing a higher pulmonary toxicity is interesting, and as the authors point out, such gender differences in respiratory diseases have been reported in previous studies. However, the observed "gender differences..." would be strengthened with a discussion of how differences in the weights of female and male C57BL/6 mice was accounted for. At 7-8 weeks, when Shvedova et al. began their acute exposures, female C57BL/6 mice have an average weight of $18 \mathrm{~g}$ while male mice have an average weight of $23 \mathrm{~g}$ [2], more than a $20 \%$ difference, which might explain the greater responses in female mice because of the higher dose per unit BW in females. The authors state the 
C57BL/6 mice used in their study weighed $20.0 \pm 1.9 \mathrm{~g}$, but a discussion of the weight distributions of males and females used in their study was not provided, it certainly would strengthen the interpretation of results. The observed gender differences might simply be explained by lower body weights of females, resulting in higher doses than males when standardized with body weight.

As mentioned, the results of the study are difficult to interpret in terms of human health impact, given its overall design. Specifically, the exposure method (pharyngeal aspiration of bolus doses) and examination of effects from a single concentration ( $240 \mu \mathrm{g} /$ mouse cumulative exposure), equivalent to a very high deposited dose in humans, requires closer examination. Shvedova et al. estimated that the $\mathrm{CNC}$ dose administered to mice is equivalent to a human worker exposed to the Occupational Safety \& Health Administration (OSHA) limit for 42 days. However, it is scientifically not justifiable in terms of effects to equate a deposited bolus dose (exposure duration is a fraction of a minute) with the same dose achieved after an exposure for many days in the lung. A more realistic comparison of the dose in mice to the dose deposited in workers' lungs has to consider the following: Key is that there is a difference in effects and underlying mechanisms induced by very high $v s$. very low dose rates [3]. Effects induced by high bolus-type delivery can be used for hazard identification, provided that dose-response data are established to determine a slope [4]. Unfortunately, though, results from such studies cannot be used for risk characterization (establishing limit values).

The principle of our approach for mouse-human extrapolation modeling involves the following steps: We used the Multiple-Path Particle Dosimetry (MPPD) model (Version 3.04) to determine the deposited fraction inhaled by a $20 \mathrm{~g}$ mouse of an aerosol with mass median aerodynamic diameter (MMAD) of $0.6 \mu \mathrm{m}$ and geometric standard deviation (GSD) of 2.0 and aerosol density of 1 . Respiratory parameters (tidal volume and breathing frequency) were allometrically adjusted to body weight which is essential when running the MPPD model. The model derived deposition fraction in the alveolar region of the mouse lung gave a value of $5.1 \%$.

As a next step, an estimate of the deposited dose in humans over an $8 \mathrm{~h}(\mathrm{hr})$ workplace exposure was performed, at a concentration of $5 \mathrm{mg} / \mathrm{m}^{3}$, which is the OSHA occupational limit for respirable cellulose dust. The deposition fraction in the alveolar region of the human lung, using the MPPD model with the MMAD and GSD given above, turned out to be $8.1 \%$. The 8 -h deposited dose in the alveolar region under light physical exercise breathing conditions was calculated as $3,985 \mu \mathrm{g} /$ day at $5 \mathrm{mg} / \mathrm{m}^{3}$ exposure concentration. This is equivalent to $6.3 \mathrm{ng} / \mathrm{cm}^{2}$ of the alveolar surface area $\left(634,620 \mathrm{~cm}^{2}\right.$ at functional residual capacity [FRC]) in the human lung. The equivalent deposited dose in the mouse by inhalation would then be $3.3 \mu \mathrm{g} /$ mouse for a one day $(8 \mathrm{~h})$ exposure (mouse alveolar surface area at FRC of $\left.526 \mathrm{~cm}^{2} \times 6.3 \mathrm{ng} / \mathrm{cm}^{2}\right)$. This is 12 times less than the $40 \mu \mathrm{g} /$ mouse delivered in the study. In addition, as mentioned above, the impact of an 8-h inhalation exposure $v s$. a less than a minute bolus delivery has to be considered.

Finally, in order to determine a mouse equivalent inhalation exposure concentration that results in the same deposited lung dose as human workers deposit when exposed to the OSHA limit of $5 \mathrm{mg} / \mathrm{m}^{3}$ for $8 \mathrm{~h}$, we used the following correlation:

Deposited Dose $=$ Minute Ventilation $\mathrm{x}$ Expos. Concentration $x$ Depos. Fraction x Expos. Duration

(The deposited dose over $8 \mathrm{~h}$ is $3.3 \mu \mathrm{g} /$ mouse; the MPPD derived deposition fraction is 0.051 [see above]; body weight allometrically adjusted tidal volume and breathing frequency for a $20 \mathrm{~g}$ mouse are $0.148 \mathrm{ml}$ and $252 / \mathrm{min}$, respectively; and exposure duration is $8 \mathrm{~h}$ ). Rearranging and solving the above equation for Exposure Concentration gives a value of $3.6 \mathrm{mg} / \mathrm{m}^{3}$, which is in a similar range as the OSHA exposure limit for workers.

However to simulate the bolus type delivery used in the mouse study, the dose of $3.3 \mu \mathrm{g} /$ mouse would have to be inhaled in one minute - rather than $8 \mathrm{~h}$ - at an exposure concentration of $1.73 \mathrm{~g} / \mathrm{m}^{3}$. Nobody would claim this Exposure Concentration to be realistic; and yet, that is exactly the equivalent to bolus-type dosing in terms of the dose delivered to the respiratory tract. Unfortunately, this has been done - and continues to be done, and accepted without question - in numerous other studies. (Additional issues of unequal distribution between aspiration and inhalation are not considered here).

Conclusions from this derivation of a human/mouse equivalent dose in the alveolar region are: $(i)$ Shvedova et al. exceeded the estimated human daily deposited dose-at the Permissible Exposure Limit allowable by OSHA - by a factor of 12 when dosing the mice. (ii) simulating the bolus type delivery with inhalation would require a highly unrealistic exposure concentration in the $\mathrm{g} / \mathrm{m}^{3}$ range of extremely short duration; (iii) effects and induction of underlying mechanisms are due to the high, unrealistic and unphysiological exposure conditions which have to be interpreted with great caution [5]. Part of any study must be a critical assessment of the relevance of administered doses in animal (and in vitro) experimental studies in order to avoid erroneous conclusions. For example, the reported significant gender differences in this study may be simply a result of differences in male/female body size if doses have not been adjusted; or are they due to the study design of only one very high dose? Again, determining the slope of a dose-response relationship would be essential to answer these and other questions. We encourage further 
discussion of the importance of dosing, which would include more details of our dosimetric calculations.

In order to comment on the possible human toxicity of CNCs, the authors should have investigated several doses in order to demonstrate response related to dose of $\mathrm{CNC}$ exposure. This is especially important given that high-dose effects in in vivo studies are inherently difficult to interpret. It is well documented that dosedependent transitions in the principle mechanism of toxicity occur at high exposures [5]; for example, high doses - amplified by very high dose rates - may result in non-linearity of responses, effects occurring from saturated receptor pathways (for both activating and detoxifying interactions), and inflammation due to conditions of overwhelming defenses [5] that are not representative of effects from realistic dose exposures.

The lack of negative and positive controls of known agents, together with the lack of different doses to characterize dose-response relationships, limits the ability to conclude there are substance-specific effects rather than as result of inflammation due to simple foreign particle introduction resulting from a bolus, high-dose exposure; similar outcomes are known to occur from high doses of any poorly soluble dust. The study design incorporates interesting measures of gene and protein expression following exposure, however the issue is not discussed regarding whether these high dose responses relate specifically to $\mathrm{CNC}$, or might similarly occur due to common respiratory triggers (such as other fibrous and non-fibrous particle types) at these exposure levels. The lack of low dose testing similarly limits interpretation of the gene and cytokine responses.
We question, further, why the abstract includes an unexpected statement comparing $\mathrm{CNC}$ to both carbon nanotubes and asbestos, never to be mentioned again in the paper. A comparison to asbestos as a positive benchmark control was not part of the study design, neither was a negative benchmark included. Adding such benchmarks combined with a dose-response approach - would have enhanced the study beyond a simple design by allowing to rank $\mathrm{CNC}$ against well-characterized benchmarks. Without this, referring to asbestos solely in the abstract is unwarranted and unjustified.

The sulfated CNCs examined by Shvedova et al. were $158 \mathrm{~nm}$ long and are not classifiable as World Health Organization (WHO) fibers [6]. Additionally, they are 1-2 orders of magnitude shorter than fibers we would expect to induce mechanisms that lead to toxicity under the asbestos fiber toxicity paradigm, where fibers longer than $15-20 \mu \mathrm{m}$ are critical [7]. We are not suggesting that inhalation of high doses of CNCs would not cause the inflammatory response observed by Shvedova et al., however the toxicity observed is better expressed in terms of the very high lung burden, rather than comparing it in the abstract to asbestos.

In summary, readers of "Particle and Fibre Toxicology" should recognize that the study outlined by Shvedova et al. was an investigation into gender differences of pulmonary toxicity from bolus-type lung exposure at a high dose of a poorly soluble dust. The conclusions that can be drawn about the pulmonary toxicity of $\mathrm{CNCs}$ - that very high doses of CNCs cause inflammation - are common to even benign fibrous and non-fibrous particles.

\section{Authors' response to: comment on Shvedova et al. (2016), “gender differences in murine pulmonary responses elicited by cellulose nanocrystals"}

Anna A. Shvedova ${ }^{1,3^{*}}$, Elena R. Kisin ${ }^{1}$, Naveena Yanamala ${ }^{1}$, Mariana T. Farcas ${ }^{1}$, Autumn L. Menas ${ }^{1}$, Andrew Williams ${ }^{4}$, Philip M. Fournier ${ }^{5}$, Jeffrey S. Reynolds ${ }^{2}$, Dmitriy W. Gutkin ${ }^{6}$, Alexander Star ${ }^{5}$, Richard S. Reiner ${ }^{7}$, Sabina Halappanavar ${ }^{4}$ and Valerian E. Kagan ${ }^{8,9}$

\footnotetext{
'Exposure Assessment Branch, NIOSH/CDC, Morgantown, WV, USA

Engineering and Controls Technology Branch, NIOSH/CDC, Morgantown, WV, USA

${ }^{3}$ Department of Physiology \& Pharmacology, School of Medicine/WVU, Morgantown WV, USA

${ }^{4}$ Environmental and Radiation Health Sciences Directorate, Health Canada, Ottawa, Ontario K1A OK9, Canada

${ }^{5}$ Department of Chemistry, University of Pittsburgh, Pittsburgh, PA, USA

${ }^{6}$ Department Pathology, University of Pittsburgh, Pittsburgh, PA, USA

${ }^{7}$ Forest Product Laboratory, USDA Forest Service, Madison, WI, USA

${ }^{8}$ Free Radical Center, University of Pittsburgh, Pittsburgh, USA

${ }^{9}$ Department of Environmental \& Occupational Health, University of Pittsburgh, Pittsburgh, PA, USA
} 
We would like to thank Drs. Shatkin and Oberdörster for their interest and comments on our paper [1] and we would like to take this opportunity to clarify some of the issues raised. One of the specific comments is focused on the relevance of our original findings to differences in the total body weights between the female and male mice. Our study determined the respiratory toxicological endpoints after several pharyngeal aspiration exposures to cellulose nanocrystals $(\mathrm{CNC})$ in male and female mice with a specific focus on the comparison of the relative responses associated with gender differences. Significant differences in the responses to respirable $\mathrm{CNC}$ with a higher pulmonary toxicity in female mice were described. However, Shatkin and Oberdörster suggest that these differences might be due to the lower body weights of female mice, resulting in higher relative doses vs males. Accumulating evidence suggests that gender can have a profound effect on incidence and severity of a variety of pulmonary diseases [8-10]. It is well known that changes in the lung volume/mass, rather than body weight, define the respiratory abnormalities. Additionally, it has been established that the lung volume/mass of male and female mice of the same age are not different, in spite of the differences in the body weights [11, 12]. As per Environmental Health Criteria 239 [13], the tissue dose which is the amount distributed to and present in a specific tissue of interest, in this case - the lung, would be in fact, the same for male and female mice. In our study, only the pulmonary responses were compared between male and female mice: inflammation and damage, TGF- $\beta$, and collagen, oxidative stress and pulmonary functions as well as the global mRNA expression were measured in lung. Thus, the comment on the employed doses with respect to the total weight differences between males and females is without merit. We maintain that the stronger responses to $\mathrm{CNC}$ documented in female mice were due to the gender associated differences in the pulmonary reactivity, rather than to $14 \%$ variance in the total body weight between the female and male mice. We thank Shatkin and Oberdörster for raising this issue in their letter [14], and the opportunity to expand our discussions. Further the comment by Shatkin and Oberdörster was useful as it allowed us to explain an important point: that in spite of the slight differences in the total body weight between female and male mice - there was essentially no gender differences between the lungs of the animals either in terms of their weight/area or functions.

Shatkin and Oberdörster expressed concerns that the dosages employed in this study exceeded the estimated human daily deposited dose - at the Permissible Exposure Limit allowable by OSHA - by a factor of 12 . It has to be acknowledged that direct quantitative comparisons between rodent and human toxicological assessments are difficult to make. This is due to uncertainties associated with various methods/tools available for modeling nanomaterial deposition in the lungs and/or differences in the physicochemical characteristics inherent to each material being investigated, as well as those related to each species. With full understanding of these limitations, the dose responses in mice can still provide useful information for meaningful modeling and approximate evaluations relevant to realistic human exposure scenarios. Several mathematical models, including the MPPD method preferred by Shatkin and Oberdörster, have been developed and used by various groups to improve translation of the in vivo rodent assessments to corresponding human equivalent exposures [15-18]. In our study, mice were exposed over an 18 day period to 6 single doses (once every 3 days) of $40 \mu \mathrm{g}$ of $\mathrm{CNC}$ materials using a pharyngeal aspiration technique (cumulative dose $\sim 240 \mu \mathrm{g}$ /mouse) in lieu of a single bolus dose. Therefore, for estimating human equivalent exposures to attain similar lung burdens, we opted to make several assumptions including no clearance over the 18 day period and the equivalency of the exposure dose to the dose deposited in the alveolar region. In our comparisons, we first estimated lung burden in rodent models, then normalized it to lung burden/ alveolar epithelial surface area to further estimate human equivalent exposure time period as follows.

Human Alveolar Deposition $=$ Exposure Concentration $\mathrm{x}$ Ventilation/8 h working $x$ Deposition Fraction

- OSHA Conc. of allowable exposure to Cellulose = $5 \mathrm{mg} / \mathrm{m}^{3}$ (respirable fraction)

- Ventilation $/ 8 \mathrm{~h}$ working $\left(20 \mathrm{~L} / \mathrm{min}^{*} 0.001 \mathrm{~m}^{3} / \mathrm{L}\right.$ * $60 \mathrm{~min} / \mathrm{h} * 8 \mathrm{~h} /$ day $)=9.6 \mathrm{~m}^{3} / \mathrm{d}([19])$

- Deposition fraction for $\mathrm{CNC}$ having largest dimension $\sim 100-300 \mathrm{~nm}[13]=\sim 15 \%([19,20])$

- Total alveolar surface area of human lung = $634,620 \mathrm{~cm}^{2}$ at functional residual capacity [FRC]

- Mouse alveolar surface area $=526 \mathrm{~cm}^{2}$ at FRC.

Based on this, the lung burden in humans per day can be estimated as $7200 \mu \mathrm{g}$ or $11.4 \mathrm{ng} / \mathrm{cm}^{2}$ per day. Thus, the accumulated alveolar lung burden in humans ignoring the clearance and other potential factors over 18 days will be $18 * 11.4=\sim 205 \mathrm{ng} / \mathrm{cm}^{2}$. The $\mathrm{T}_{1 / 2}$ for alveolar clearance in humans is $\sim 1$ year and can be ignored in these estimates, as the clearance would be insignificant over the 18 days required to achieve the equivalent worker lung burden. Assuming that the CNC particles administered through pharyngeal aspiration deposit predominantly in the deep lungs (the alveolar region), the dose employed in mice would result in a lung burden of $\sim 0.456 \mu \mathrm{g} / \mathrm{cm}^{2}$ or $456 \mathrm{ng} / \mathrm{cm}^{2}$, i.e. only $\sim 2.3$ times higher than can be expected from equivalent exposures per day in humans. Thus we estimated that the human equivalent lung burden would be achieved in 
$\sim 42$ days $(2.3 \times 18$ days $=41.4$ days $)$. It has to be noted that if the total dust concentrations, instead of respirable fraction, of OSHA Permissible Exposure Limit (PEL $15 \mathrm{mg} / \mathrm{m}^{3}$ ) or NIOSH Recommended Exposure Limit (REL $-10 \mathrm{mg} / \mathrm{m}^{3}$ ) were considered, then the respective human alveolar lung burden would be equivalent to $34 \mathrm{ng} / \mathrm{cm}^{2}$ or $23 \mathrm{ng} / \mathrm{cm}^{2}$, respectively. Over 18 days, this would result in the accumulation of 612 or $414 \mathrm{ng} / \mathrm{cm}^{2}$, which are slightly higher than or closer to the average $\mathrm{CNC}$ dose in mice per day employed in our study. Moreover, the employed exposure regimen and concentrations over 3-weeks of exposure are further justified as one considers that humans may be exposed chronically for longer periods of times.

Can the effects reported in our study be due to nonlinear responses stemming from receptor oversaturation pathways and/or conditions of overwhelming the defenses-lung overload phenomenon? So far, this has been demonstrated in rats, but not in mice or humans. Porter et al. [21, 22] demonstrated that a lung burden of $6 \mathrm{mg} / \mathrm{rat}$ of exposure to silica particles (alveolar surface area $\sim 0.4 \mathrm{~m}^{2}$ of rat lung $[23,24]$ had not reached overload and had not decreased the clearance rate. This is equivalent to $0.9 \mathrm{mg} /$ mouse lung (alveolar surface area $\sim 0.06 \mathrm{~m}^{2}$ of mouse lung $[23,24]$ ) which is $\sim 4$ times higher than the concentrations of $\mathrm{CNC}$ (up to $240 \mu \mathrm{g} /$ mouse) we have investigated in several of our studies [1, 25, 26]. Importantly, several studies indicated that the dose dependent effects of nanomaterials were mostly linear within this dose range.[25].

Shatkin and Oberdörster overlooked one of the most essential experimental features of our study [1]: the employment of chronic treatments achieved by scheduled repeated exposures (twice a week for 3 weeks resulting in an accumulated dose of $240 \mu \mathrm{g}$ ) to deliver $\mathrm{CNC}$ by pharyngeal aspiration. This regimen achieves the accumulation of particles in the lung over time, which is closer to potential occupational exposures than a single daily bolus dose (as supposed by Shatkin and Oberdörster). Importantly, this protocol may be one of the best ways to dose animals in cases when generation of nanomaterial aerosol for inhalation studies (eg, nano-cellulose materials) could represent technical difficulties [27]. Several studies have documented the noninvasive and reproducible character of particle deposition and clearance from the mouse lower respiratory tract after pharyngeal aspiration [28, 29]. Moreover, direct comparisons of bolus inhalation vs aspiration exposures of SWCNTs further demonstrated the efficiency of the aspiration technique in studies of fibrous particles [30]. The repeated exposure regimens have been employed by others for pharyngeal aspiration [18, 31-33] and intra-tracheal instillation exposures [34-37]. Furthermore, the deposition estimates using MPPD model (v3.0) preferred by Shatkin and
Oberdörster also have several limitations. These include (a) deposition models for mouse are based on only two strains (BALBC and B6C3F1) - both of which are models for either asthmatic or polygenic diseases, (b) calculations on mouse extrapolation are based on experimental data for spherical particles, whereas CNC particles with elongated structures could exhibit different kinetics, (c) generally low estimates of alveolar surface area $\left(64.5 \mathrm{~m}^{2}\right.$ vs $102 \mathrm{~m}^{2}$ for humans and $0.03 \mathrm{~m}^{2}$ vs $0.06 \mathrm{~m}^{2}$ for mice), and (d) consideration of endotracheal vs nose-only exposure.

Why did we choose a cumulative dose of $240 \mu \mathrm{g} /$ mouse? We agree that determining the slope of a dose-response relationship is important for the assessment of the relevance of the mouse doses used in our study to human exposures. The dose response of bolus adverse effects of $\mathrm{CNC}$ exposure $(50-200 \mu \mathrm{g} /$ mouse $)$ in mice by pharyngeal route has been published previously [25]. Our study described dose-dependent effects assessed by several outcomes including inflammation, cytokine/chemokine release, pulmonary damage, and oxidative stress markers - protein carbonyls and 4-hydroxynonenal. Accordingly, the doses selected for repeated exposure regimen in this study were similar to our low-dose bolus exposure ( $40 \mu \mathrm{g} /$ mouse) given to mice twice a week for 3 weeks thus reaching cumulative dose of $240 \mu \mathrm{g} /$ mouse closer to the highest $\mathrm{CNC}$ bolus dose.

Shatkin and Oberdörster [14] further commented on the lack of positive and/or negative controls in our study. Our previous work demonstrated that asbestos administration (employed as a positive control) at the same lowest $\mathrm{CNC}$ dose $(50 \mu \mathrm{g} / \mathrm{mouse})$ demonstrated lower acute toxicity compared to $\mathrm{CNC}$ particles at equal mass concentration [38]. While detailed comparisons of pulmonary toxicity and long term effects of cellulose nanocrystals with asbestos and other fibrous materials (e.g., CNTs, CNF...) are definitely of great interest, they were not the topic of this study and we are not suggesting from our present data that $\mathrm{CNC}$ are asbestos-like with respect to the spectrum of asbestos induced diseases. We share the common opinion that such studies, together with the comparison of inhalation studies, are essential for the further assessment of possible human toxicity of CNCs.

Finally, Shatkin and Oberdörster [14] question whether comparisons of $\mathrm{CNC}$ to carbon nanotubes and asbestos was necessary in the abstract. It is common knowledge in the field of nanotoxicology that high aspect ratio materials, particularly carbon nanotubes, can be potentially pathogenic like asbestos. The similarity in mechanisms and pathways of toxicity have been articulated and emphasized in many published papers and included in their titles or abstracts [39-46] as well as in studies of nanocellulose materials [25, 47-49]. Thus, while not directly investigated in the current 
study, this paradigm has been widely accepted by the toxicology community, it was not directly investigated in the current study and we agree that this inference should have been left out.

In summary, we do not believe that the slight differences in the total body weights of female and male C57BL/6 mice contributed to the elevated responses in female mice upon exposure to $\mathrm{CNC}$. Our study was aimed at the investigation of gender differences of pulmonary toxicity from repeated pharyngeal aspiration exposures to $\mathrm{CNC}$ materials in mice, rather than exploration of dose-response effects of CNCs. We believe this study representing a "proof of principle" or "hypothesis forming" study [27], was an investigation into gender differences of pulmonary toxicity from repeated pulmonary aspiration exposure to $\mathrm{CNC}$ and needs to be followed up by long term inhalation studies, as rightfully emphasized by Shatkin and Oberdörster [14]. Further, the specific gene expression changes related to carbohydrate/pattern /polysaccharide and glycosaminoglycan binding and signaling, as detailed in our paper, support a biological response as a result of CNC exposure. Taken together, our data provide evidence that raise doubts concerning the validity of the conclusion drawn by Shatkin and Oberdörster [14] that very high doses of CNCs cause inflammation and that such pulmonary responses are common to even benign fibrous and non-fibrous particles. However, we do agree that there is a critical need for further detailed research aimed at mechanistic understanding of potential risks of human exposure to CNCs. Studies in our research group, detailing the pulmonary effects of $\mathrm{CNCs}$ via inhalation exposure route at relevant exposure limits, are currently underway. Finally, we would like to thank Shatkin and Oberdörster for their thought provoking commentary [14] highlighting the critical need for continuous research aimed at better understanding of the potential significance and risk for human exposures to CNCs.

\section{Abbreviations}

CNC: Cellulose nanocrystals; FRC: Functional residual capacity; GSD: Geometric standard deviation; MMAD: Mass median aerodynamic diameter; MPPD: Multiple-Path Particle Dosimetry; OSHA: Occupational Safety \& Health Administration; WHO: World Health Organization

\section{Acknowledgements}

The authors acknowledge the support of James D. Ede and Kimberly J. Ong, independent consultants for Vireo Advisors LLC in preparing this letter.

\section{Funding}

Not applicable.

\section{Availability of data and materials}

All data generated or analyzed during this study are available from the corresponding author on reasonable request.

\section{Authors' contributions}

JAS prepared the first draft of this commentary; GO provided additional comments specifically related to dosimetry. Both authors read and approved the final manuscript.

\section{Competing interests}

JAS is president of Vireo Advisors LLC, an advisory firm to public and private organizations, including those seeking to commercialize nanomaterials.

\section{Consent for publication}

Not applicable.

\section{Ethics approval and consent to participate}

Not applicable.

\section{Author details}

${ }^{1}$ Vireo Advisors LLC, Boston, MA, USA. ${ }^{2}$ University of Rochester, School of Medicine and Dentistry, Rochester, NY, USA.

Received: 21 August 2016 Accepted: 18 October 2016

Published online: 04 November 2016

\section{References}

1. Shvedova AA, Kisin ER, Yanamala N, Farcas MT, Menas AL, Williams A, et al. Gender differences in murine pulmonary responses elicited by cellulose nanocrystals. Part Fibre Toxicol. 2016;13(1):28. doi:10.1186/s12989-016-0140-x. http:/www.ncbi.nlm.nih.gov/pubmed/27278671.

2. Animal Resources Centre: Rat and mice weights. http://www.arc.wa.gov.au/ ?page_id=125 (2016). Accessed Jun 232016.

3. Baisch BL, Corson NM, Wade-Mercer P, Gelein R, Kennell AJ, Oberdörster G, Elder A. Equivalent titanium dioxide nanoparticle deposition by intratracheal instillation and whole body inhalation: the effect of dose rate on acute respiratory tract inflammation. Part Fibre Toxicol. 2014;11:5.

4. Driscoll K, Costa D, Hatch G, Henderson R, Oberdörster G, Salem H, Schlesinger R. Intratracheal instillation as an exposure technique for the evaluation of respiratory tract toxicity: uses and limitations. Toxicol Sci. 2000;55:24-35.

5. Slikker W, Andersen ME, Bogdanffy MS, Bus JS, Cohen SD, Conolly RB, David RM, Doerrer NG, Dorman DC, Gaylor DW, Hattis D, Rogers JM, Setzer W, Swenberg JA, Wallace K. Dose-dependent transitions in mechanisms of toxicity. Toxicol Appl Pharmacol. 2004;201:203-25.

6. World Health Organization. Determination of airborne fibre number concentrations. 1997; http://www.who.int/occupational_health/publications/ airfibre/en/. Accessed 23 June 2016.

7. Donaldson K, Murphy F, Schinwald A, Duffin R, Poland CA. Identifying the pulmonary hazard of high aspect ratio nanoparticles to enable their safetyby-design. Nanomedicine. 2011;6:143-56.

8. Carey MA, Card JW, Voltz JW, Germolec DR, Korach KS, Zeldin DC. The impact of sex and sex hormones on lung physiology and disease: lessons from animal studies. Am J Physiol Lung Cell Mol Physiol. 2007;293(2):L272-8. doi:10.1152/ ajplung.00174.2007. http://www.ncbi.nlm.nih.gov/pubmed/17575008.

9. Chen B, Kan H. Air pollution and population health: a global challenge. Environ Health Prev Med. 2008;13(2):94-101. doi:10.1007/s12199-007-0018-5. http://www.ncbi.nlm.nih.gov/pubmed/19568887.

10. Carey MA, Card JW, Voltz JW, Arbes Jr SJ, Germolec DR, Korach KS, et al. It's all about sex: gender, lung development and lung disease. TEM. 2007;18(8): 308-13. doi:10.1016/j.tem.2007.08.003

11. Brass DM, McGee SP, Dunkel MK, Reilly SM, Tobolewski JM, Sabo-Attwood T, et al. Gender influences the response to experimental silica-induced lung fibrosis in mice. Am J Physiol Lung Cell Mol Physiol. 2010;299(5):L664-71. doi: 10.1152/ajplung.00389.2009. http://www.ncbi.nlm.nih.gov/pubmed/20729388.

12. Hadden H, Soldin SJ, Massaro D. Circadian disruption alters mouse lung clock gene expression and lung mechanics. J Appl Physiol (1985). 2012; 113(3):385-92. doi:10.1152/japplphysiol.00244.2012. http://www.ncbi.nlm.nih. gov/pubmed/22678966

13. Environmental Health Criteria 239: Principles for Modeling Dose-response for the Risk Assessment of Chemicals. Edited by IPCS WHO 2009. Geneva: World Health Organization.

14. Shatkin JA, Oberdorster G. Comment on Shvedova et al. (2016), "Gender differences in murine pulmonary responses elicited by cellulose nanocrystals". Part Fibre Toxicol. 2016

15. Siegrist KJ, Reynolds SH, Kashon ML, Lowry DT, Dong C, Hubbs AF, et al. Genotoxicity of multi-walled carbon nanotubes at occupationally relevant doses. Part Fibre Toxicol. 2014;11:6. doi:10.1186/1743-8977-11-6. http://www. ncbi.nlm.nih.gov/pubmed/24479647.

16. Sargent LM, Porter DW, Staska LM, Hubbs AF, Lowry DT, Battelli L, et al. Promotion of lung adenocarcinoma following inhalation exposure to multi- 
walled carbon nanotubes. Part Fibre Toxicol. 2014;11:3. doi:10.1186/17438977-11-3. http://www.ncbi.nlm.nih.gov/pubmed/24405760.

17. NIOSH. Occupational Exposure to Carbon Nanotubes and Nanofibers. Cincinnati: Department of Health and Human Services, Public Health Service, Centers for Disease Control, National Institute for Occupational Safety and Health; 2010. DHHS (NIOSH) Docket Number: NIOSH 161-A; Available at http://www.cdc.gov/niosh/docket/review/docketA/.

18. Erdely A, Dahm M, Chen BT, Zeidler-Erdely PC, Fernback JE, Birch ME, et al. Carbon nanotube dosimetry: from workplace exposure assessment to inhalation toxicology. Part Fibre Toxicol. 2013;10(1):53. doi:10.1186/17438977-10-53. http://www.ncbi.nlm.nih.gov/pubmed/24144386.

19. ICRP: Human Respiratory Tract Model for Radiological Protection. vol. 24 Ann. ICRP 1994:1-482.

20. Geiser M, Kreyling WG. Deposition and biokinetics of inhaled nanoparticles. Part Fibre Toxicol. 2010;7:2. doi:10.1186/1743-8977-7-2. http://www.ncbi.nlm. nih.gov/pubmed/20205860.

21. Porter DW, Ye J, Ma J, Barger M, Robinson VA, Ramsey D, et al. Time course of pulmonary response of rats to inhalation of crystalline silica: NF-kappa B activation, inflammation, cytokine production, and damage. Inhal Toxicol. 2002;14(4):349-67. doi:10.1080/08958370252870998. http://www.ncbi.nlm. nih.gov/pubmed/12028809.

22. Porter DW, Ramsey D, Hubbs AF, Battelli L, Ma J, Barger M, et al. Time course of pulmonary response of rats to inhalation of crystalline silica: histological results and biochemical indices of damage, lipidosis, and fibrosis. J Environ Pathol Toxicol Oncol. 2001;20 Suppl 1:1-14. http://www. ncbi.nlm.nih.gov/pubmed/11570667.

23. Stone KC, Mercer RR, Freeman BA, Chang LY, Crapo JD. Distribution of lung cell numbers and volumes between alveolar and nonalveolar tissue. Am Rev Respir Dis. 1992;146(2):454-6. doi:10.1164/ajrccm/146.2.454. http://www.ncbi.nlm.nih.gov/pubmed/1489139.

24. Stone KC, Mercer RR, Gehr P, Stockstill B, Crapo JD. Allometric relationships of cell numbers and size in the mammalian lung. Am J Respir Cell Mol Biol. 1992;6(2):235-43. doi:10.1165/ajrcmb/6.2.235. http://www.ncbi.nlm.nih.gov/ pubmed/1540387.

25. Yanamala N, Farcas MT, Hatfield MK, Kisin ER, Kagan VE, Geraci CL, et al. In Vivo Evaluation of the Pulmonary Toxicity of Cellulose Nanocrystals: A Renewable and Sustainable Nanomaterial of the Future. ACS Sustain Chem Eng. 2014;2(7):1691-8. doi:10.1021/sc500153k. http://www.ncbi.nlm.nih.gov/pubmed/26753107.

26. Farcas MT, Kisin ER, Menas AL, Gutkin DW, Star A, Reiner RS, et al. Pulmonary exposure to cellulose nanocrystals caused deleterious effects to reproductive system in male mice. J Toxicol Environ Health A. 2016:1-14; doi: 10.1080/ 15287394.2016.1211045. http://www.ncbi.nlm.nih.gov/pubmed/27558875.

27. Oberdorster G, Castranova V, Asgharian B, Sayre P. Inhalation Exposure to Carbon Nanotubes (CNT) and Carbon Nanofibers (CNF): Methodology and Dosimetry. J Toxicol Environ Health B Crit Rev. 2015;18(3-4):121-212. doi:10.1080/10937404. 2015.1051611. http://www.ncbi.nlm.nih.gov/pubmed/26361791.

28. Rao GV, Tinkle S, Weissman DN, Antonini JM, Kashon ML, Salmen R, et al. Efficacy of a technique for exposing the mouse lung to particles aspirated from the pharynx. J Toxicol Environ Health A. 2003;66(15):1441-52. doi:10. 1080/15287390306417. http://www.ncbi.nlm.nih.gov/pubmed/12857634.

29. Foster WM, Walters DM, Longphre M, Macri K, Miller LM. Methodology for the measurement of mucociliary function in the mouse by scintigraphy. J Appl Physiol (1985). 2001;90(3):1111-7. http://www.ncbi.nlm.nih.gov/ pubmed/11181627.

30. Shvedova AA, Kisin E, Murray AR, Johnson VJ, Gorelik O, Arepalli S, et al. Inhalation vs. aspiration of single-walled carbon nanotubes in C57BL/6 mice: inflammation, fibrosis, oxidative stress, and mutagenesis. Am J Physiol Lung Cell Mol Physiol. 2008;295(4):L552-65. doi:10.1152/ajplung.90287.2008. http://www.ncbi.nlm.nih.gov/pubmed/18658273.

31. Zeidler-Erdely PC, Kashon ML, Battelli LA, Young SH, Erdely A, Roberts JR, et al. Pulmonary inflammation and tumor induction in lung tumor susceptible $A / J$ and resistant C57BL/6 J mice exposed to welding fume. Part Fibre Toxicol. 2008:5:12. doi:10.1186/1743-8977-5-12. http//www.ncbi.nlm.nih.gov/pubmed/18778475.

32. Zeidler-Erdely PC, Kashon ML, Li S, Antonini JM. Response of the mouse lung transcriptome to welding fume: effects of stainless and mild steel fumes on lung gene expression in AJJ and C57BL/6 J mice. Respir Res. 2010;11:70. doi:10.1186/ 1465-9921-11-70. http://www.ncbi.nlm.nih.gov/pubmed/20525249.

33. Zeidler-Erdely PC, Meighan TG, Erdely A, Battelli LA, Kashon ML, Keane M, et al. Lung tumor promotion by chromium-containing welding particulate matter in a mouse model. Part Fibre Toxicol. 2013;10:45. doi:10.1186/17438977-10-45. http://www.ncbi.nlm.nih.gov/pubmed/24107379.
34. Inoue K, Yanagisawa R, Koike E, Nishikawa M, Takano H. Repeated pulmonary exposure to single-walled carbon nanotubes exacerbates allergic inflammation of the airway: Possible role of oxidative stress. Free Radic Biol Med. 2010;48(7):924-34. doi:10.1016/j.jreeradbiomed.2010.01.013. http:/www.ncbi.nlm. nih.gov/pubmed/20093178.

35. Inoue $\mathrm{K}$, Koike E, Yanagisawa R, Hirano S, Nishikawa M, Takano H. Effects of multi-walled carbon nanotubes on a murine allergic airway inflammation model. Toxicol Appl Pharmacol. 2009;237(3):306-16. doi:10.1016/j.taap.2009. 04.003. http://www.ncbi.nlm.nih.gov/pubmed/19371758.

36. Ban M, Langonne I, Huguet N, Goutet M. Effect of submicron and nano-iron oxide particles on pulmonary immunity in mice. Toxicol Lett. 2012;210(3):267-75. doi:10.1016/.toxlet.2012.02.004. http://www.ncbi.nlm.nih.gov/pubmed/22343040.

37. Ban M, Langonne I, Huguet N, Guichard Y, Goutet M. Iron oxide particles modulate the ovalbumin-induced Th2 immune response in mice. Toxicol Lett. 2013;216(1):31-9. doi:10.1016/j.toxlet.2012.11.003. http://www.ncbi.nlm. nih.gov/pubmed/23147377.

38. Yanamala N, Farcas MT, Hatfield MK, Kisin ER, Kagan VE, Geraci CL, et al. In Vivo Evaluation of the Pulmonary Toxicity of Cellulose Nanocrystals: A Renewable and Sustainable Nanomaterial of the Future. ACS Sustain Chem Eng. 2014;2(7): 1691-8. doi:10.1021/sc500153k. http://dx.doi.org/10.1021/sc500153k.

39. Donaldson K, Murphy F, Schinwald A, Duffin R, Poland CA. Identifying the pulmonary hazard of high aspect ratio nanoparticles to enable their safetyby-design. Nanomedicine (Lond). 2011;6(1):143-56. doi:10.2217/nnm.10.139. http://www.ncbi.nlm.nih.gov/pubmed/21182425.

40. Donaldson K, Poland CA. Inhaled nanoparticles and lung cancer - what we can learn from conventional particle toxicology. Swiss Med Wkly. 2012;142:W13547. doi:10.4414/smw.2012.13547. http://www.ncbi.nlm.nih.gov/pubmed/22714122.

41. Donaldson K, Poland CA, Murphy FA, MacFarlane M, Chernova T, Schinwald A. Pulmonary toxicity of carbon nanotubes and asbestos - similarities and differences. Adv Drug Deliv Rev. 2013;65(15):2078-86. doi:10.1016/j.addr. 2013.07.014. http://www.ncbi.nlm.nih.gov/pubmed/23899865.

42. Kane AB, Hurt RH. Nanotoxicology: the asbestos analogy revisited. Nat Nanotechnol. 2008;3(7):378-9. doi:10.1038/nnano.2008.182. http://www.ncbi. nlm.nih.gov/pubmed/18654556.

43. Osmond-McLeod MJ, Poland CA, Murphy F, Waddington L, Morris H, Hawkins SC, et al. Durability and inflammogenic impact of carbon nanotubes compared with asbestos fibres. Part Fibre Toxicol. 2011;8:15. doi:10.1186/1743-8977-8-15. http://www.ncbi.nlm.nih.gov/pubmed/21569450.

44. Sanchez VC, Pietruska JR, Miselis NR, Hurt RH, Kane AB. Biopersistence and potential adverse health impacts of fibrous nanomaterials: what have we learned from asbestos? Wiley Interdiscip Rev Nanomed Nanobiotechnol. 2009;1(5):511-29. doi:10.1002/wnan.41. http.//www.ncbi.nlm.nih.gov/pubmed/20049814.

45. Sanchez VC, Weston P, Yan A, Hurt RH, Kane AB. A 3-dimensional in vitro model of epithelioid granulomas induced by high aspect ratio nanomaterials. Part Fibre Toxicol. 2011;8:17. doi:10.1186/1743-8977-8-17. http://www.ncbi.nlm.nih.gov/pubmed/21592387.

46. Schinwald A, Murphy FA, Prina-Mello A, Poland CA, Byrne F, Movia D, et al. The threshold length for fiber-induced acute pleural inflammation: shedding light on the early events in asbestos-induced mesothelioma. Toxicol Sci. 2012;128(2):461-70. doi:10.1093/toxsci/kfs171. http://www.ncbi. nlm.nih.gov/pubmed/22584686.

47. Endes C, Mueller S, Kinnear C, Vanhecke D, Foster EJ, Petri-Fink A, et al. Fate of cellulose nanocrystal aerosols deposited on the lung cell surface in vitro. Biomacromolecules. 2015;16(4):1267-75. doi:10.1021/acs.biomac.5b00055. http://www.ncbi.nlm.nih.gov/pubmed/25789784.

48. Endes C, Schmid O, Kinnear C, Mueller S, Camarero-Espinosa S, Vanhecke D, et al. An in vitro testing strategy towards mimicking the inhalation of high aspect ratio nanoparticles. Part Fibre Toxicol. 2014;11:40. doi:10.1186/s12989014-0040-x. http://www.ncbi.nlm.nih.gov/pubmed/25245637.

49. Endes C, Müller S, Schmid O, Vanhecke D, Foster EJ, Petri-Fink A, et al. Risk assessment of released cellulose nanocrystals - mimicking inhalatory exposure. J Phys Conf Ser. 2013;429(1):012008. http://stacks.iop.org/1742$6596 / 429 / i=1 / a=012008$. 